include the deposition and distribution of documents, and diffusion of information. In particular, it is suggested that the organisation should provide at its central depot a universal primary bibliography, and should endeavour to secure the creation of a universal copyright system. It seems that with the establishment of the United Nations Educational, Scientific and Cultural Organisation, the proposals should, in the first instance, be considered by that body, presumably at the instance of one or other of the national delegations.

\section{Literature of Spectrochemical Analysis}

THE American Society for Testing Materials, through its Committee on Spectrographic Analysis, has sponsored the publication of two indexes on the literature of spectrochemical analysis. The first, issued in 1940, covered the years $1920-39$ and contained 1,467 references and a detailed subject index. The second, "Index to the Literature on Spectrochemical Analysis. Part II, 1940-1945", issued in January of this year, gives references to 1,044 publications on spectrochemical analysis that have appeared during the years $1940-45$ inclusive. In addition, there are thirty-six references, for the years 1938 and 1939, that were omitted from the earlier Index. The references are arranged in chronological order, and for each year the material is listed in alphabetical order according to the authors. English titles are given for all the papers, but foreign book titles are left untranslated. In the earlier Index abstracts were not given but only references to the published abstracts of the papers. Because of the widely scattered nature of the literature, and because many libraries probably lack complete sets of foreign periodicals for the war years, a brief abstract is provided, in Part II, for every spectrochemical publication listed. In most cases the abstracts are quoted verbatim from Chemical Abstracts, but where necessary, by consulting other abstracting journals and the original articles, a more suitable abstract has been compiled. This painstaking and intensive work, both of maintaining and compiling the Index, has been done under the direction of B. F. Scribner and W. F. Meggers, of the National Bureau of Standards, Washington. A helpful, detailed subject index, which covers the content rather than the titles of the several papers, completes the Index.

It is somewhat surprising that in spite of war-time restrictions on publication and the difficulties of access to foreign journals so much work has been done in the field of spectrochemical analysis during the War. The choice of spectrochemical methods in preference to others can only be attributed to the simplicity, speed, sensitivity and economy of these methods-all vital factors in war-time applications. With the return of industrial competition, these methods should prove equally valuable, and all spectrographers will find both Part II and the earlier Index indispensable as reference handbooks. The Index is clearly printed and bound in a paper cover, though for reference purposes in the laboratory it would have been preferable to have had a much heavier binding. Abbreviations are used extensively, and although no explanatory list is provided, no real difficulty will be experienced in understanding the text. The addition of a list of the full titles and addresses of periodicals to which reference is made would perhaps be an improvement. Copies of the Index can be obtained from A.S.T.M. Headquarters, 1916 Race Street, Philadelphia 3, Pasadena.

\section{Nature Lover: The Magazine of the Countryside}

THe recent publication of volume 4, No. 1 of Nature Lover, the magazine of the countryside, marks the revival of a much-needed popular journal which deals with the natural history and archæology of the British countryside. The greatest merit of the journal is that it chooses good, representative subject. matter which is fairly easily available, thus bringing these rural sciences within the reach of everyman. The present number contains short, readable articles on the "Unity of Nature" by C. H. Warren, "Secretive Badgers" by B. M. Nicholas, "British Fritillary Butterflies" by L. H. Newman, "Jimmy the Lizard" by Frances Pitt, "The Numbers of Animals" by Brian Vesey-Fitzgerald, "Water Problems of Fishes" by Chapman Pincher, "Some Strange Plant Habits" by Wolseley Banks, "Bird-watching on an East Coast Estuary" by R. H. Harrison, "Lavenham, Suffolk" by Geoffrey Morgan. Among these authors are some of Britain's best natural history writers, and some of the articles are illustrated by good photographs. This monthly journal can be strongly recommended to the general lay reader who is interested in country-life and natural history, and it should be encouraged in all our secondary schools, for its method of presentation is bound to stimulate interest. Subscription to Nature Lover is $16 s$. 6d. a year, including postage. Further information can be obtained from Nature Lover, Staples House, Cavendish Place, London, W.1.

\section{U.S. National Academy of Sciences : Officers}

According to the annual statement, the present officers and members of the Council of the U.S. National Academy of Sciences are as follow : President: Prof. Alfred N. Richards, professor of pharmacology, University of Pennsylvania ; Vice-President : Dean L. P. Eisenhart, Graduate School of Mathematics, Princeton University; Foreign Secretary : Prof. Detlev W. Bronk, Johnson professor of biophysies, University of Pennsylvania ; Home Secretary : Dr. F. E. Wright, Geophysical Laboratory, Carnegie Institution, Washington; Treasurer: Dr. J. C. Hunsaker, Departments of Mechanical Engineering and Aeronautical Engineering, Massachusetts Institute of Technology. Other Members of Council: Dr. Walter R. Miles, Prof. W. Albert Noyes, jun., Prof. I. I. Rabi, Dr. W. M. Stanley, Dean John T. Tate and Dr. D. D. Van Slyke.

\section{Rook Behaviour during Incubation}

CLOSELY studying a rookery of eight nests during the incubation period, C. M. Ogilvie noticed that the hen birds applied themselves almost exclusively to incubation, while excursions were rare and very brief. (British Birds, 40, No. 5 ; May, 1947.) Feeding and coition, when this occurred, took place upon the nest. The cock bird was responsible for feeding the hen, a duty which was performed with characteristic ceremony at irregular intervals; intrusions within the colony and invasions from without were combated by the male birds. Coition was more often promiscuous than between mated pairs, and took the form of an assault resisted by the hen and countered by other cocks.

\section{University of Leeds: Appointments}

THE following appointments in the University of Leeds have been announced: Mr. E. A. Vaughan, lecturer in the Department of Social Studies; Mr. 
A. Johnson and Mr. L. G. Johnson, lecturers in the Departments of Economics and Extra-Mural Studies ; Mr. Edward Broadhead, lecturer in zoology; Mr. J. D. Jonkins, lecturer in mining; Mr. H. J. King, lecturer in surveying; Dr. W. J. Allen and Dr. R. A. Kenney, lecturers in physiology; Mr. S. Dagley, lecturer in biochemistry; Mr. G. A. Nelson, lecturer in pharmacognosy.

The number of full-time students enrolled for the present session is 2,804 ; the number of ex-Service students at present in the University is approximately 1,200. The present total of students compares with 1,736 in 1938 ; the number of arts students has increased very markedly owing to the number of students returning to complete courses interrupted by national service, but apart from this the increase is fairly uniformly spread over all departments and faculties.

\section{University of Sheffield : Appointments}

THe following appointments have been made in the University of Sheffield: Dr. A. S. C. Lawrence, senior lecturer in physical chemistry ; Dr. H. J. Tress, lecturer in glass technology; H. Graetzer, assistant lecturer in mathematics; G. H. Jowett, assistant lecturer in statistics in the Department of Mathematics ; J. R. Beattie, assistant lecturer in physics; Douglas W. Riley, assistant lecturer in chomistry; H. J. Whiteley, assistant lecturer in pathology.

The following resignations have been announced: Dr. J. Sinclair, senior lecturer in mining, who has been appointed to the chair of mining at University College, Cardiff; Dr. F. Bielschowsky, cancer research worker in the Department of Pathology under the British Empire Cancer Campaign, who has been appointed director of cancer research for New Zealand.

\section{The Night Sky in November}

NEW moon occurs on Nov. 12d. 20h. 0lm., U.T., and full moon on Nov. $28 \mathrm{~d} .08 \mathrm{~h}$. $45 \mathrm{~m}$. The following conjunctions with the moon take place: Nov. 6d. 03h., Mars $4^{\circ}$ S.; Nov. 6d. 07h., Saturn $5^{\circ}$ S. ; Nov. 11d. 20h., Mercury $0 \cdot 03^{\circ}$ S. ; Nov. 14d. 0lh., Jupiter $2^{\circ}$ N. ; Nov. 14 d. 10 h., Venus $1^{\circ}$ N. In addition to these conjunctions with the moon, the following conjunctions also take place: Nov. 9d. 14h., Venus in conjunction with Jupiter, Venus $0.9^{\circ} \mathrm{S}$.; Nov. 11d. $18 \mathrm{~h}$., Mars in conjunction with Saturn, Mars $0.9^{\circ} \mathrm{N}$. Mercury is in inferior conjunction on Nov. 5 and becomes a morning star later in the month, rising at 5h. $40 \mathrm{~m}$., and $6 \mathrm{~h}$. at the middle and end of the month, respectively. Venus, an evening star, sets about $17 \mathrm{~h}$. throughout November and can be seen very low in the western sky. Mars, in the constellation of Leo, rises at $23 \mathrm{~h} .08 \mathrm{~m}, 22 \mathrm{~h} .52 \mathrm{~m}$, and $22 \mathrm{~h} .25 \mathrm{~m}$., at the beginning, middle and end of the month respectively, and is close to Regulus towards the end of November. Jupiter sets in the early evening hours and is unobservable. Saturn rises at $23 \mathrm{~h}$. $38 \mathrm{~m}$., and $21 \mathrm{~h}$. $50 \mathrm{~m}$. at the beginning and end of the month, respectively, and can be seen in the constellation of Leo, fairly close to Mars. Occultations of stars brighter than magnitude 6 are as follows: Nov. 1d. 04h. $25 \cdot 5 \mathrm{~m}$., v Taur. $(D)$; Nov. 1d. 05h. $08 \cdot 9 \mathrm{~m}$., v Taur. $(R)$; Nov. Id. $19 \mathrm{~h}$. $53 \cdot 0 \mathrm{~m} ., 103$ Taur. $(R)$; Nov. 2d. 05h. $33 \cdot 2 \mathrm{~m} ., 118$ Taur. $f .(R)$; Nov. 7d. 04h. $32 \cdot 1 \mathrm{~m} ., 46$ Leon. $(R)$; Nov. 21d. 18h. 17.3m., $\tau$ Aqar. $(D)$; Nov. 26d. 20h. 37.0m., $\sigma$ Arie $(D)$; Nov. 29d. 23h. 33.0m., 139 Taur. $(R) . \quad D$ and $R$ refer to disappearance and reappearance, respectively, and the latitude of Greenwich is assumed. There will be an annular eclipse of the sun on Nov. 12, invisible at Greenwich.

\section{Announcements}

Prof. Arthur Holimes, regius professor of geology in the University of Edinburgh, has been elected a foreign member of the Royal Swedish Academy of Sciences.

THE Kelvin Medal Award Committee, consisting of the presidents of the Institutions of Civil Engineers, Mechanical Engineers, Electrical Engineers, Naval Architects, Mining and Metallurgy, Mining Engineers, and Engineers and Shipbuilders in Scotland, and the Iron and Steel Institute, has awarded the Kelvin Gold Medal for 1947 to Air Commodore F. G. Whittlo, in recognition of the eminent services he has rendered to engineering science in those branches of engineering work with which Lord Kelvin was especially identified. The Medal is normally presented triennially, but the last award was made in 1938 to Sir J. J. Thomson.

Dr. Joskef Aronson, of the United States Bureau of Indian Affairs, has been awarded the Alvarenga Prize of 1947 of the College of Physicians of Philadelphia, in recognition of his studies on the evaluation of $B C G$ vaccine in the control of tuberculosis.

AT the invitation of the British National Committee, the fourth plenary World Power Conference will be held in London in 1950.

THE International Union of Biological Sciences, with the financial support of the United Nations Educational, Scientific and Cultural Organisation, is arranging a symposium on the role of trace elements in plant physiology, to be held at Rothamsted Experimental Station during November 5-6, 1947. Seventeen research workers from Australia, Denmark, Finland, France, Great Britain, Netherlands, Norway, Sweden, Switzerland and the United States have accepted invitations to attend. The report on this symposium will be published by the International Union.

THE Linnean Society of London, in conjunction with the Systematics Association, is organising a course of twelve weekly lectures on the "Principles and Methods of Taxonomy". Lectures will be given in the rooms of the Linnean Society on Wednesdays at 5.30 p.m., the first lecture being on October 29 . Leading plant and animal taxonomists are contributing to the course, which is open to advanced students of biology. Further information can be obtained from the Assistant Secrotary, Linnean Society of London, Burlington House, Piccadilly, London, W.1.

A Faraday Socrexy general discussion on "The Physical Chemistry of Process Metallurgy" will be held in the latter half of September 1948. It is intended that the discussion should be devoted to the thermodynamies and kinetics of the high-tem. perature reactions involved in smelting and refining, but excluding reactions which occur in mechanical working and heat treatment, and also electrochemical processes in aqueous solutions. Thermodynamics will include thermochemical, free energy and equilibrium studies, and kinetics will include both chemical reactions and diffusion processes. Prospective contributors should forward to the Secretary of the Society summaries of any papers they would like to submit not later than February 1. 